\title{
Omega 3 fatty acid for the prevention of dementia (Review)
}

\author{
Lim WS, Gammack JK, Van Niekerk JK, Dangour A
}

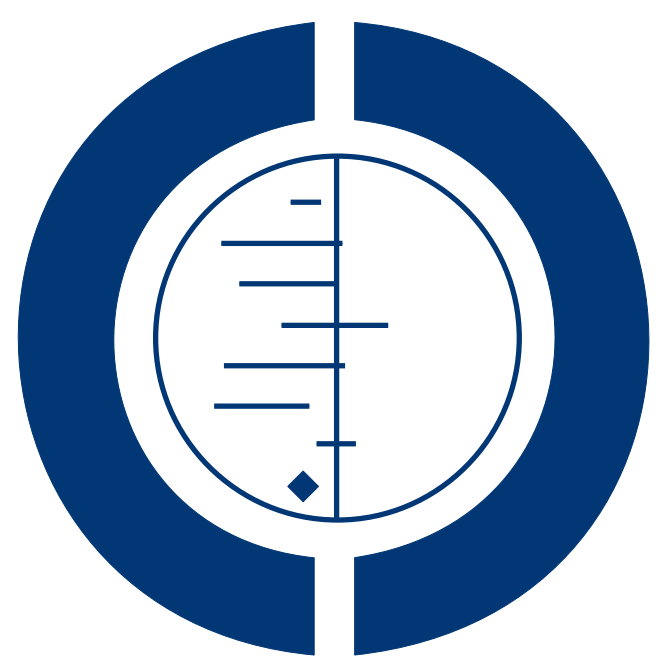

\section{THE COCHRANE COLLABORATION $^{\circledR}$}

This is a reprint of a Cochrane review, prepared and maintained by The Cochrane Collaboration and published in The Cochrane Library 2006, Issue 1

http://www.thecochranelibrary.com

\section{WILEY}

Omega 3 fatty acid for the prevention of dementia (Review)

Copyright @ 2009 The Cochrane Collaboration. Published by John Wiley \& Sons, Ltd. 
TABLE OF CONTENTS

HEADER . . . . . . . . . . . . . . . . . . . . . . . . . . . . . . . . . . . . 1

ABSTRACT . . . . . . . . . . . . . . . . . . . . . . . . . . . . . . . . . . . . . . . . . . . .

PLAIN LANGUAGE SUMMARY . . . . . . . . . . . . . . . . . . . . . . . . . . . . . . . . . . . 2

BACKGROUND . . . . . . . . . . . . . . . . . . . . . . . . . . . . . . . . . . . . . . . . .

OBJECTIVES . . . . . . . . . . . . . . . . . . . . . . . . . . . . . . . . . . . . . .

METHODS . . . . . . . . . . . . . . . . . . . . . . . . . . . . . . . . . . . . . . 4

RESULTS . . . . . . . . . . . . . . . . . . . . . . . . . . . . . . . . . . . . . . . 8

DISCUSSION . . . . . . . . . . . . . . . . . . . . . . . . . . . . . . . . . . . . . 8

AUTHORS' CONCLUSIONS . . . . . . . . . . . . . . . . . . . . . . . . . . . . . . . . . 8

ACKNOWLEDGEMENTS . . . . . . . . . . . . . . . . . . . . . . . . . . . . . . . . . 8

REFERENCES . . . . . . . . . . . . . . . . . . . . . . . . . . . . . . . . . . . . . . 9

CHARACTERISTICS OF STUDIES . . . . . . . . . . . . . . . . . . . . . . . . . . . . . . . . . . 11

DATA AND ANALYSES . . . . . . . . . . . . . . . . . . . . . . . . . . . . . . . . . . . . . . . . . . . . . .

WHAT'S NEW . . . . . . . . . . . . . . . . . . . . . . . . . . . . . . . . . . . . . 14

HISTORY . . . . . . . . . . . . . . . . . . . . . . . . . . . . . . . . . . . . . . . 14

CONTRIBUTIONS OF AUTHORS . . . . . . . . . . . . . . . . . . . . . . . . . . . . . . . . . . . . . . 14

DECLARATIONS OF INTEREST . . . . . . . . . . . . . . . . . . . . . . . . . . . . . . . 14

INDEX TERMS . . . . . . . . . . . . . . . . . . . . . . . . . . . . . . . . . . . . . 15

Omega 3 fatty acid for the prevention of dementia (Review)

Copyright $\odot 2009$ The Cochrane Collaboration. Published by John Wiley \& Sons, Ltd. 


\title{
[Intervention Review]
}

\section{Omega 3 fatty acid for the prevention of dementia}

\author{
Wee-Shiong Lim ${ }^{1}$, Julie K Gammack ${ }^{2}$, Jan K Van Niekerk ${ }^{3}$, Alan Dangour ${ }^{4}$ \\ ${ }^{1}$ Department of Geriatric Medicine, Tan Tock Seng Hospital, Singapore, Singapore. ${ }^{2}$ Department of Internal Medicine, Division \\ of Geriatric Medicine, St. Louis University, St. Louis, USA. ${ }^{3}$ Department of Psychology, Fulbourn Hospital, Cambridge, UK. \\ ${ }^{4}$ Department of Epidemiology and Population Health, Nutrition and Public Health Intervention Research Unit, London, UK \\ Contact address: Wee-Shiong Lim, Department of Geriatric Medicine, Tan Tock Seng Hospital, 11 Jalan Tan Tock Seng, Singapore, \\ 308433, Singapore. Wee_Shiong_Lim@ttsh.com.sg.
}

Editorial group: Cochrane Dementia and Cognitive Improvement Group.

Publication status and date: Edited (no change to conclusions), published in Issue 1, 2009.

Review content assessed as up-to-date: 11 November 2005.

Citation: Lim WS, Gammack JK, Van Niekerk JK, Dangour A. Omega 3 fatty acid for the prevention of dementia. Cochrane Database of Systematic Reviews 2006, Issue 1. Art. No.: CD005379. DOI: 10.1002/14651858.CD005379.pub2.

Copyright (C) 2009 The Cochrane Collaboration. Published by John Wiley \& Sons, Ltd.

\begin{abstract}
A B S T R A C T
Background

Accruing evidence from observational and epidemiological studies suggests an inverse relationship between dietary intake of omega 3 polyunsaturated fatty acid (PUFA) and risk of dementia. Postulated mechanisms that might qualify omega 3 PUFA as an interventional target for the primary prevention of dementia include its anti-atherogenic, anti-inflammatory, anti-oxidant, anti-amyloid and neuroprotective properties.
\end{abstract}

\section{Objectives}

To review the evidence that omega 3 PUFA supplementation prevents cognitive impairment and dementia in cognitively intact elderly persons.

\section{Search methods}

The Cochrane Dementia and Cognitive Improvement Group's (CDCIG) Specialized register, MEDLINE, EMBASE,CINAHL PsycINFO, AMED AND CENTRAL and several ongoing trials databases were searched on 5 and 6 October 2005. The CDCIG Register is updated regularly and contains records from all major medical databases and many ongoing trials databases.

\section{Selection criteria}

In order to be selected, trials needed to be randomized, placebo-controlled, doubled blinded, of minimum study duration of 6 months, involved persons aged 60 years and above without pre-existing dementia at study onset, and employed cognitive endpoints.

\section{Data collection and analysis}

Reviewers, working independently, were to select, quality assess and extract relevant data where appropriate and possible. In comparing intervention with placebo, the pooled odds ratios or weighted mean differences and standardized mean difference were to be estimated.

\section{Main results}

There were no randomized trials found in the search that met the selection criteria. Results of two clinical trials are expected in 2008.

Omega 3 fatty acid for the prevention of dementia (Review)

Copyright $\odot 2009$ The Cochrane Collaboration. Published by John Wiley \& Sons, Ltd. 


\section{Authors' conclusions}

There is a growing body of evidence from biological, observational and epidemiological studies that suggests a protective effect of omega 3 PUFA against dementia. However, until data from randomized trials become available for analysis, there is no good evidence to support the use of dietary or supplemental omega 3 PUFA for the prevention of cognitive impairment or dementia.

\section{PLAIN LANGUAGE SUMMARY}

There is no evidence that dietary or supplemental omega 3 polyunsaturated fatty acid (PUFA) reduces the risk of cognitive impairment or dementia in healthy elderly persons without pre-existing dementia

Evidence from biological and epidemiological studies suggests that lower omega 3 PUFA intake is associated with an increased risk of dementia. In experimental animal models, dietary enhancement of docosahexanoic acid (a long-chain omega 3 PUFA) slows the expression of Alzheimer's pathology and improves cognitive performance. These findings raise the possibility of similar preventative benefits in humans. Omega 3 PUFA have also being shown to reduce vascular risk, inflammation and oxidative damage. Available clinical studies comparing the occurrence of Alzheimer's disease between elderly persons with different levels of dietary omega 3 PUFA intake, suggest that risk of Alzheimer's disease is significantly reduced among those with higher levels of fish and omega 3 PUFA consumption. However, because these studies are not randomized trials, they provide insufficient evidence to recommend dietary and supplemental omega 3 PUFA for the explicit purpose of dementia prevention.

This review yielded no clinical trials that could confirm or refute the utility of omega 3 PUFA in preventing cognitive impairment or dementia. This is an important area that is in pressing need of further research.

\section{B A C K G R O U N D}

Congruent with the graying demographic trend in many developed countries, it is projected that there will be an exponential rise in the prevalence of age-associated diseases like dementia. It has been estimated, based on demographic projections, that between 1990 and 2010, the number of cases of Alzheimer's disease (AD) in developed countries will rise by nearly $40 \%$. Dementia is a progressive debilitating syndrome that imposes a huge burden of care on individual caregivers, health care professionals, and resource utilization, especially institutionalized care. Current therapeutic approaches do not reverse the progression of the disease, and often only offer short-term symptomatic improvement (Cummings 2004). In the current economic climate of increasing health care costs and tightening health care budgets, there is a pressing need for effective preventative measures of dementia.

Studies suggest that the pathogenesis of dementia involves the complex interactions between genetic and environmental risk factors. In recent years, there has been an increased interest in nutrition as an important modifiable environmental risk factor. Nutrients and metabolites such as folic acid, vitamin B12, vitamin B6 and homocysteine have been the focus of attention (Nourhasémi 2000). This interest has widened to encompass the investigation of an implicating role of low omega 3 polyunsaturated fatty acid
(PUFA) status in the etiology of dementia. This is supported by studies suggesting that omega 3 PUFA consumption may be beneficial in the treatment of other neuropsychiatric conditions such as depression (Hibbeln 1998) and bipolar affective disorder (Stoll 1999).

Omega 3 PUFAs have been in the limelight since the astute observation by Bang in the 1970s that the Greenland Inuit had low mortality from coronary artery disease despite a diet that is rich in fat (Bang 1971). It was proposed that this could be because of the high content of omega 3 fatty acid in the Inuit diet, which consisted largely of fish, seal and whale (Dyerberg 1975). The marine sources of omega 3 PUFA (also called n-3 PUFA) include eicosapentanoic acid (EPA or 20:5), docosahexanoic acid (DHA, 22:6) and docosapentanoic acid (DPA, 22:5), which are the longer chain omega 3 forms. Alpha linolenic acid (ALA, 18:3) is the shorter chain omega 3 fatty acid from nuts and vegetable oils. Although an endogenous process exists whereby ALA can be partially converted to the longer chain omega 3 fatty acids, there is some debate about the effectiveness of this conversion, depending on other dietary factors and whether assessed over short or long term. For this reason, the effectiveness of ALA may differ from that of the longer chain forms (Hooper 2004).

Several mechanisms have been postulated for the protective role of

Omega 3 fatty acid for the prevention of dementia (Review)

Copyright $\odot 2009$ The Cochrane Collaboration. Published by John Wiley \& Sons, Ltd. 
omega 3 PUFA in dementia. Firstly, omega 3 PUFA may protect against dementia by reducing cardiovascular disease (Tully 2003) and non-haemorrhagic stroke risk (He 2002; Iso 2001). Cardiovascular disease has been shown to increase the risk of dementia and its major subtypes, AD and vascular dementia (Hofman 1997). The beneficial effects of long chain PUFA in reducing vascular risk include antiarrhythmic, antithrombotic, anti-inflammatory and antiatherogenic effects (Friedland 2003). Omega 3 PUFA may also lower serum triglyceride levels, lower blood pressure and improve endothelial function (Din 2004). Secondly, omega 3 PUFA may reduce dementia risk by reducing the synthesis of pro-inflammatory cytokines, and thereby, attenuate the pro-inflammatory components of the dementia disease process (Akiyama 2000). Thirdly, since DHA is a primary component of membrane phospholipids in the brain, adequate omega 3 PUFA status may protect against dementia by the maintenance of membrane integrity and neuronal function. In animal models, dietary enhancement of DHA was shown to promote neuronal membrane excitability, increase neurotransmitter levels, and reduce neuronal damage (Morris 2003b). In behavioural models, this translated into superior learning acquisition and memory performance over animals fed control diets (Calon 2004; Gamoh 1999). Lastly, omega 3 PUFA may play a pivotal role in the expression of $B$-amyloid, a major component of the hallmark plaque pathology in Alzheimer's disease, by reducing its production from amyloid precursor protein and increasing its clearance (Friedland 2003).

A cross-sectional study reported that higher fatty fish and marine omega 3 PUFA consumption was associated with a reduced risk of impaired cognitive performance in a middle-aged population (Kalmijn 2004). Corroborative evidence of an inverse relationship between fish or omega 3 PUFA intake and risk of dementia can be found in observational (Conquer 2000; Tully 2003; Ruggiero 2004) and epidemiological studies (BarbergerGateau2002; Huang 2005; Kyle 1999; Morris 2003a; Morris 2003b). The epidemiological studies are large population-based studies with a prospective design and reasonable duration of follow up (3.9 to 10 years). However, several methodological concerns deserve mention. In the Chicago Health and Aging Project, the self-reported food frequency questionnaire was administered just 2 years before clinical diagnosis of dementia (Morris 2003a; Morris 2003b). Thus, bias from subclinical dementia cannot be excluded; the observed association with omega 3 PUFA levels may be a consequence of altered dietary habits rather than a cause of cognitive decline. In the PAQUID (Personnes Ageés QUID) study, dietary data was limited to only 4 frequencies of intake without collecting information for specific fat groups, and vitamin $\mathrm{E}$ intake was not adjusted for in the analysis (Barberger-Gateau2002). The Cardiovascular Health Cognition Study likewise did not adjust for vitamin $\mathrm{E}$ in the analysis; also, adjustment by education and income attenuated the benefits of fatty fish on dementia risk (Huang 2005). Lastly, the results of Kyle et al were preliminary and only presented in a one-page research letter with few methodological details (Kyle 1999).

Moreover, the evidence of an inverse relationship between omega 3 PUFA intake and risk of dementia is not unambiguous. While an inverse association between cognitive decline with age and omega 3 PUFA was reported in a population-based study that examined fatty acid composition of erythrocyte membranes (Heude 2003), this was not replicated in a recent prospective cohort study that utilised dietary questionnaire to assess fatty acid intake (Morris 2005). This study found that dietary intake of fish was associated with slower cognitive decline with age over a 6 year follow-up, although there was no consistent association with omega 3 fatty acids, suggesting the possibility that the protective effect of fatty fish consumption may not be fully accounted for by omega-3 PUFA. The Rotterdam study did not demonstrate any influence of low omega 3 PUFA intake on dementia risk after a mean followup of 6 years, thereby not confirming the positive findings of an earlier report on the same study which was based on a shorter follow up of 2 years and a smaller number of incident dementia cases (Kalmijn 1997; Engelhart 2002). Likewise, the Canadian Study of Health and Aging did not find any beneficial effects from omega 3 PUFA (Laurin 2003). In addition, interventional studies of omega 3 fatty acids in dementia are limited, and tend to be small in numbers and of short follow up duration (Terano 1999; Yehuda 1996). Larger scale clinical interventional trials examining the effect of increased omega 3 intake on coronary artery disease tend not to examine dementia risk or cognition endpoints.

Given that most omega-3 PUFA are ingested in the form of oily fish or fish oil capsules, reports of environmental contamination with various toxic compounds such as mercury, dioxin and polychlorinated biphenyls (PCBs) are disconcerting. Adult exposures to dioxins and PCBs may lead to an excess of total cancers, while high mercury levels in some fish species may attenuate their cardioprotective effects (Guallar 2002). A recent Cochrane review did not demonstrate an adverse effect of dietary or supplemental omega-3 PUFA on total mortality, combined cardiovascular events or cancers in people with or at high risk of cardiovascular disease, and in the general population (Hooper 2004). Some reports show that fish oil may worsen glycemic control in diabetes, but two meta-analyses found no adverse effect (Friedberg 1998; Montori 2000).

The cumulative summation of many small protective effects of omega 3 PUFA may add up to a significant protective effect on dementia risk and age-related cognitive decline. Thus, this systematic review aims to pool together the evidence to examine the effect of omega 3 PUFA in the primary prevention of dementia in the non-demented population.

\section{O B JE C T IVES}

\section{Primary}


To determine from available evidence whether dietary or supplemental omega 3 fatty acid is effective in the primary prevention of dementia in non-demented older persons.

\section{Secondary}

To review the benefit of treatment with omega 3 fatty acid on cognition measures, and whether its protective effect (if any) is dependent on the dose.

\section{METHODS}

\section{Criteria for considering studies for this review}

\section{Types of studies}

This review is restricted to all randomized controlled trials (RCTs) in non-demented participants where omega 3 PUFA was compared with placebo, provided that there was a minimum follow up of 6 months (26 weeks or 180 days) and dementia was excluded at baseline. Studies which do not have cognitive endpoints (defined as either incident dementia or measurement on a cognition rating scale or instrument) are excluded.

There is no restriction on language, publication type and sample size. Trials are excluded if the allocation of treatment and placebo was not random.

If a study meets all the criteria for inclusion but does not present sufficient data allowing an estimate of effect (and this information is not available from the authors), the study is treated as a "dropout" instead of being excluded, and listed in a table of eligible studies to indicate that it has not been overlooked.

\section{Types of participants}

Eligible participants include persons aged 60 years and above, without a diagnosis of dementia or cognitive impairment at study onset. The chief consideration for the age cut-off is to ensure a characteristic representation of the neurodegenerative diseases that are typically seen in older persons (such as Alzheimer's disease), as the heterogeneous subset of young onset dementias are often due to underlying illnesses that are very different in etiology, presentation, and rate of progression from that encountered in the elderly population.

Subjects with a diagnosis of delirium and acute confusion at study onset are excluded.

There should be a demonstration of adequate screening to exclude pre-existing dementia or cognitive impairment via the use of $\operatorname{cog}$ nitive instruments, dementia rating scales or psychometric tests that have been reported in peer-reviewed journals. Subjects with known cognitive impairment but not amounting to dementia are excluded from this review. These include (but are not limited to) the following diagnostic categories: dementia prodrome, incipient dementia, cognitive impairment no dementia (CIND), mild cognitive impairment (MCI), vascular cognitive impairment (VCI), age-associated memory impairment (AAMI), and age associated cognitive decline (AACD). While some of these terms were conceptually meant to characterize memory changes reflecting a "normal" stage of aging, more recent data has cast some doubt on this premise (Ritchie 2000). In particular, MCI has been recognized as a diagnostically heterogeneous entity with a significant progression to dementia (Petersen 2001).

There is no restriction on the basis of gender, ethnicity, study setting or other characteristics.

\section{Types of interventions}

Any type of omega 3 PUFA treatments, as monotherapy or in combination with other pharmacological treatment (including vitamins), if the design allows the effect of omega 3 PUFA to be isolated. There are broadly two types of omega 3 treatment of relevance:

i) longer chain omega 3 PUFA: eicosapentanoic acid (EPA), docosahexanoic acid (DHA) or docosapentanoic acid (DPA), either individually or in combination, and/or

ii) shorter chain PUFA such as alpha linolenic acid (ALA).

The intervention should involve dietary supplementation or a provided diet. There is no restriction on dose or dosing schedule. Studies are excluded if the intervention consisted solely of dietary advice, or if the intervention was based solely on self report without definitive provision of dietary supplements (usually in the form of pills or oils) or a diet. In studies where the intervention consisted of a provided diet, these would still be eligible if treatment was compared with usual diet. Otherwise, trials where treatment was compared with another active treatment and not to a placebo, are excluded.

Studies are also excluded if they include multiple risk factor intervention on lifestyle factors other than diet and supplementation (unless the effect of diet or supplementation can be separated out from the other interventions).

\section{Types of outcome measures}

\section{Primary outcome}

Incident dementia of any cause as defined by accepted international diagnostic criteria, such as those of the International Classification of Diseases (ICD-10: WHO 1992), American Psychiatric Association Diagnostic and Statistical Manual of Mental Disorders (DSM III-R; DSM-IV), and the National Institute of Neurological and Communicative Disorders and Stroke and the Alzheimer's disease and Related Disorders Association (NINCDS-ADRDA: McKhann 1984). 


\section{Secondary outcomes}

Mean change in measures of memory and cognitive function from baseline to follow-up as measured by peer-reviewed mental status tests such as the Mini-Mental State Examination (MMSE), or more detailed psychometric assessment such as the Wechsler Memory Scale.

Proportion reporting progression using peer reviewed global rating scales such as the Clinical dementia Rating (CDR).

Mean change in measures of validated health-related quality of life such as the SF-36 (Ware 1993).

Behavioural outcomes relating to depression and anxiety using accepted international criteria such as the DSM criteria, or validated rating scales such as the Geriatric Depression Scale (Gompertz 1993), Hamilton Depression Inventory and Hamilton Anxiety Rating scale (Hamilton 1960), Hospital Anxiety and Depression Scale (Zigmond 1983), the Beck Depression Inventory and Beck Anxiety Inventory (Beck 1961).

As studies without cognitive endpoints will be excluded, healthrelated quality of life and mood outcomes will be collected only if present along with cognitive endpoints. Where available, outcomes of explanatory interest such as treatment dose, and blood levels of PUFA status (such as cholesteryl ester-EPA) are collected.

\section{Search methods for identification of studies}

The Cochrane Dementia and Cognitive Improvement Group's Specialised Register was searched on 5 October 2005 using the terms: Omega-3 or Omega 3 or Polyunsaturated fatty acid or PUFA or unsaturated fatty acids or Essential fatty acids or EFA or Eicosapentanoic acid or EPA or Ethyl-Eicosapentanoic acid or EEPA or Docosahexanoicacid or DHA or Docosapentanoic acid or DPA or Alpha-linolenic acid or ALA or Fish oil or n-3 fatty acids or long chain fatty acids or primrose oil or linseed oil or oily fish or flaxseed oil or fish oil.

CENTRAL (Cochrane Library issue 3, 2005) was searched on 5 October 2005 using the following search strategy:

MEDLINE (1966-2005/10, week 1) was searched on 5 October using the following search strategy:

\#1 explode "Fatty-Acids-Omega-3"/ all subheadings

\#2 "fatty acid*" or fats or omega-3 or "omega 3" or PUFA or EPA or E-EPA or DHA or DPA or ALA

\#3 n-3-fatty-acid* or "n-3 fatty acid*" or "linseed oil" or "flaxseed oil" or "fish oil" or "salmon oil" or "cod liver oil"

\#4 "eicosapentanoic acid*" or "docosahexanoic acid" or "dosapentanoic acid"” or "alpha-linolenic acid*" or "ethyl-eicosapentanoic acid $^{* \prime}$

$\# 5 \# 1$ or $\# 2$ or \#3 or \#4

\#6 explode "Primary-Prevention"/ all subheadings

\#7 prevent* or avoid*

$\# 8$ \#6 or \#7

$\# 9$ \#5 and \#8

\#10 cognit*
\#11 \#9 and cognit*

\#12 \#11 and (healthy or normal or elderly or older)

EMBASE (1980-2005/09) was searched on 6 October using the

following search strategy:

\#1 explode "fatty-acid"/ all subheadings

\#2 "fatty acid*" or fats or omega-3 or "omega 3" or PUFA or EPA or E-EPA of DHA or DPA or ALA

\#3 n-3-fatty acid* or "n-3 fatty acid*" or "linseed oil" or "flaxseed oil" or "fish oil" or "salmon oil" or "cod liver oil"

\#4 "eicosapentanoic acid*” or "docosahexanoic acid*” or "dosapentanoic acid*" or "alpha-linolenic acid*” or "ethyl-eicosapentanoic acid*

$\# 5 " \# 1$ or \#2 or \#3 or \#4

\#6 “primary-prevention”/ all subheadings

\#7 prevent* or avoid*

\#8 \#6 or \#7

$\# 9 \# 5$ and \#8

$\# 10$ \#9 and (healthy or normal or elderly or older)

\#11 \#10 and (random* or placebo* or double-blind*)

\#12 \#11 and cognit*

PsycINFO (1872-2005/09, week 4) was searched on 6 October using the following search strategy:

\#1 explode "Fatty-Acids"

\#2 "fatty acid*" or fats or omega-3 or "omega 3" or PUFA or EPA or E-EPA or DHA or DPA or ALA

\#3 n-3-fatty-acid* or "n-3 fatty acid*" or "linseed oil" or "flaxseed oil" or "fish oil" or "salmon oil" or "cod liver oil"

\#4 "eicosapentanoic acid*" or "docosahexanoic acid*" or "dosapentanoic acid*" or "alpha-linolenic acid*" or "ethyl-eicosapentanoic acid*” $^{*}$

\#5 \#1 or \#2 or \#3 or \#4

\#6 "Primary-Mental-Health-Prevention" in MJ,MN

\#7 prevent* or avoid*

$\# 8 \# 6$ or \#7

$\# 9$ \#5 and \#8

$\# 10$ \#9 and (healthy or normal or elderly or older)

\#11 \#10 and cognit*

CINAHL (1982-2005/08) was searched on 6 October using the following search strategy:

\#1 explode "Fatty-Acids-Omega-3"/ without-subheadings , administration-and-dosage, adverse-effects , antagonists-and-inhibitors, analysis, blood, cerebrospinal-fluid, classification, contraindications, drug-effects, diagnostic-use, economics, ethical-issues, history, immunology, immunology, legislation-andjurisprudence, metabolism, pharmacodynamics, physiology, pharmacokinetics, poisoning, radiation-effects, standards, therapeutic-use, urine / without-subheadings, in-adolescence, inadulthood, in- infancy-and-childhood, in-old-age, in-pregnancy , in-utero

\#2 "fatty acid*" or fats or omega-3 or "omega 3" or PUFA or EPA or E-EPA or DHA or DPA or ALA

\#3 n-3-fatty-acid* or "n-3 fatty acid*" or "linseed oil" or "flaxseed

Omega 3 fatty acid for the prevention of dementia (Review)

Copyright $\odot 2009$ The Cochrane Collaboration. Published by John Wiley \& Sons, Ltd. 
oil" or "fish oil" or "salmon oil" or "cod liver oil"

\#4 "eicosapentanoic acid*" or "docosahexanoic acid*" or "dosapentanoic acid*" or "alpha-linolenic acid*" or "ethyl-eicosapentanoic acid"” $^{*}$

$\# 5 \# 1$ or $\# 2$ or \#3 or \#4

\#6 "Preventive-Trials"/ without-subheadings, adverse-effects, classification, economics, education, ethical-issues, equipmentand-supplies, evaluation, history, immunology, legislation-andjurisprudence, methods , organizations , standards , trends , therapeutic-use , utilization / without-subheadings , in-adolescence , in-adulthood, in-infancy-and- childhood, in-old-age, in-pregnancy, in-utero

\#7 prevent* $^{*}$ or avoid*

$\# 8$ \#6 or \#7

$\# 9$ \#5 and \#8

\#10 \#9 and (healthy or normal or elderly or older)

$\# 11$ \#10 and (random* or placebo* or double-blind*)

\#12 \#11 and cognit*

AMED (1985-2005/09) was searched on 6 October using the following search strategy:

\#1 explode "FATTY-ACIDS"

\#2 "fatty acid*" or fats or omega-3 or "omega 3" or PUFA or EPA or E-EPA or DHA or DPA or ALA

\#3 n-3-fatty-acid* or "n-3 fatty acid*" or "linseed oil" or "flaxseed oil" or "fish oil" or "salmon oil" or "cod liver oil"

\#4 "eicosapentanoic acid*" or "docosahexanoic acid*" or "dosapentanoic acid"” or "alpha-linolenic acid"” or "ethyl-eicosapentanoic acid"” $^{*}$

$\# 5 \# 1$ or $\# 2$ or \#3 or \#4

\#6 "PREVENTION-" in DE,ET,MT

\#7 prevent* or avoid*

$\# 8$ \#6 or \#7

$\# 9$ \#5 and \#8

\#10 \#9 and (healthy or normal or elderly or older)

\#11 \#10 and cognit*

ClinicalTrials.gov and NRR (National Research Register - http:// www.update-software.com/projects/nrr/) were searched for ongoing trials on 6 October 2005. The search engines Copernic and Google were used with the search terms omega, trial, cognition on the same date.

The following electronic databases (all years) were also searched on 27 September 2006 using the terms: Omega-3 or Omega 3 or Polyunsaturated fatty acid or PUFA or unsaturated fatty acids or Essential fatty acids or EFA or Eicosapentanoic acid or EPA or Ethyl-Eicosapentanoic acid or E-EPA or Docosahexanoicacid or DHA or Docosapentanoic acid or DPA or Alpha-linolenic acid or ALA or Fish oil or n-3 fatty acids or long chain fatty acids or primrose oil or linseed oil or oily fish or flaxseed oil or fish oil. Where appropriate, the search was narrowed using the terms: "prevent*" or "avoid*"; "dementia"; "randomized controlled trial" or "clinical study".

- :AgeLine Databases
- Alt-HealthWatch (alternative medicine)

- Biological Abstracts[R]

- BioMed Central

- Clinical Pharmacology Database

- DIMDI (european research)

- Dissertation Abstracts

- HerbMed (alternative medicine)

- HSTAT (Health Services Technology Assessment Text

- Web of Science

In addition, review bibliographies of books and review articles, and references from retrieved articles were explored. Experts in this field were also contacted for further references and unpublished trials.

There were no time restrictions or language constraints applied.

\section{Data collection and analysis}

When studies are available for analysis, the following methods will be applied:

\section{Study selection}

Based on the title of publication and the abstract identified from the trial search, irrelevant citations will be discarded by the reviewers (WL, AD, JG and JVN). If there is any possibility that the article could be relevant, the full text article will be retrieved for further assessment. Two reviewers (WL, JG or JVN) will independently decide which trials fit the inclusion criteria. Any disagreement will be resolved by discussion between the reviewers, with referral to a third reviewer to adjudicate any persisting differences. Excluded studies and reasons for exclusion will be stated.

Assessment of methodological quality

Although there are a number of scales devised for assessing the quality of RCTs, there is no evidence that complex and time-consuming scales are more effective than simple scales. The following areas have some evidence of association with biased estimates of treatment effect (Juni 2001), and will be assessed:

a) randomization (method of generation and concealment of allocation)

b) blinding (blinding of observers / participants to the treatment allocation)

c) loss to follow-up (presence of withdrawals and loss to follow up, and the analysis of these).

The quality assessment will include an evaluation of the following components for each included study. Each component will be categorized as Adequate, Unclear, Inadequate, or Not Used, based on the following:

- Randomization (allocation generation) - adequate when the allocation sequence protects against biased allocation to the comparison groups

- Randomization (allocation concealment) - adequate when measures are taken to ensure that decision for recruitment precedes knowledge of allocation

Omega 3 fatty acid for the prevention of dementia (Review)

Copyright @ 2009 The Cochrane Collaboration. Published by John Wiley \& Sons, Ltd. 
- Blinding - adequate when the outcome assessor is unaware of the allocation

- Loss to follow up - adequate if less than $20 \%$ of participants withdrew from the trial, or were lost to follow up

- Intention to treat analysis - adequate when participants were analysed in the groups to which they were originally randomized

On the basis of the above criteria, trials will be given a quality rating of A (adequate), B (unclear), and C (inadequate), based on the quality categories as described in the Cochrane Reviewers' Handbook 4.2.2. (Alderson 2004). A description of the quality of each study will be given based on a summary of the above components.

\section{Data Extraction}

This will be performed by two reviewers (AD, JG or JVN), who will independently enter data onto a data extraction form. The extracted data will be checked for agreement between reviewers, and any discrepancies that persist after discussion will be resolved by a third reviewer (WL). Missing data will be obtained from the authors whenever possible. To avoid introducing bias, this unpublished information will be obtained in writing, on forms designed for this purpose. The data will then be entered into Review Management software (RevMan 4.2).

The following data will be collected:

- Report - author, year and source of publication

- Study - study setting, sample characteristics

- Patients - demographics, screening to exclude pre-existing cognitive impairment or dementia, absence of acute confusion or delirium at study onset, other concomitant medical conditions or medications that may affect cognition

- Research design and features - sampling mechanism, treatment assignment mechanism, blinding, drop-out rates, length of follow-up, pertinent design features (e.g. crossover design)

- Intervention - type, duration, dose, timing, mode of delivery

- Outcome - number of patients randomized, nature of outcome, estimate and standard error, adverse effects, reason for non-adherence, measurement of omega- 3 status

For continuous data, the summary statistics required for each outcome are the mean change from baseline, the standard deviation of the mean change, and the number of patients in each treatment group at each assessment. Where changes from baseline are not reported, the mean, the standard deviation and number of patients for each treatment group at each time point will be extracted if available. For binary data, the numbers in each treatment group and the numbers experiencing the outcome of interest will be sought. The baseline assessment is defined as the latest available assessment prior to commencement of intervention.

To allow an intention-to-treat analysis, the data will be sought irrespective of compliance, whether or not the patient was subsequently deemed ineligible, or otherwise excluded from treatment or follow-up. If intention-to-treat data are not available in the publications, "on-treatment" data, or the data of those who completed the trial, will be sought and indicated as such.

In studies where a cross-over design was used, only data from the first treatment phase after randomization will be eligible for inclusion.

\section{Data Analysis}

For binary outcomes, such as presence or absence of dementia, Peto odds ratio and its $95 \%$ confidence interval (CI) will be used to measure treatment effect. The number needed to treat (NNT) will also be calculated. In addition, a weighted estimate of the typical treatment effect across trials will be calculated.

With regards to outcomes measured arising from ordinal rating scales, these will be treated as continuous variables if the ordinal scale appears to be approximately normally distributed or if the analysis suggests parametric tests are appropriate. If the normal approximation is not deemed appropriate, the study will be regarded as a "dropout" rather than ineligible, and will be listed in a table of eligible studies.

For continuous variables, summary statistics (number of participants, mean and standard deviation) will be required for each outcome of each treatment group for change from baseline. For crossover trials only the data from the first treatment period will be used. When change from baseline results are not reported, the required summary statistics will be calculated from the baseline and assessment time treatment group means and standard deviations. In this case a zero correlation between the measurements at baseline and assessment time will be assumed. This method overestimates the standard deviation of the change from baseline, but this conservative approach is considered to be preferable in a meta-analysis.

The measure of the treatment difference for any outcome will be the weighted mean difference when the pooled trials use the same rating scale or test. Where different rating scales or tests are used, the trial specific summary effect will be transformed to a standardized (scale-free) mean difference, which is calculated as the absolute mean difference divided by the standard deviation.

Overall estimates of the treatment difference will be presented. A fixed-effects model will be used in the first instance but if there is evidence of heterogeneity, then either only homogeneous results will be pooled, or a random-effects model will be used (in which case the confidence intervals would be broader than those of a fixed-effects model).

If numbers permit, subgroup analysis will be performed to examine the impact of dose, composition (e.g. marine versus plant sources), baseline cognitive function (e.g. baseline MMSE) and whether Omega 3 PUFA supplementation was in isolation or an adjunct to other therapy. Reasons for heterogeneity in studies will be explored and, if necessary, sensitivity analyses will examine the effects of excluding study subgroups, e.g. those studies with lower methodological quality. If study numbers permit, a funnel plot will be used to detect publication bias. 


\section{RE S U L T S}

\section{Description of studies}

See: Characteristics of excluded studies; Characteristics of ongoing studies.

Our search yielded only 2 randomized trials in elderly persons with cognitive endpoints (Terano 1999; Yehuda 1996). Both are treatment trials in patients with established Alzheimer's disease or vascular dementia, and thus, not applicable to our review. There are no randomized trials examining the primary prevention of cognitive decline or dementia.

However, there are two ongoing randomized controlled trials with cognitive endpoints of omega 3 PUFA supplementation in healthy cognitively intact older persons that may be relevant to a future update of the review. The OPAL study (Dangour 2004) is a doubleblind randomized placebo-controlled trial examining the effect of daily supplementation with $700 \mathrm{mg}$ omega 3 PUFA (500 mg DHA and $200 \mathrm{mg}$ EPA) for 24 months on cognitive performance in healthy older persons aged 70-79 with good cognitive function (MMSE equals or greater than 24 out of 30 points at baseline) who are recruited from 20 primary care practices. It is scheduled for completion at the end of 2007. Secondly, there is the MEMO study (van de Rest 2005), which is scheduled for completion in end 2007. Elderly persons aged 65 years and above with baseline MMSE greater than 21will be randomized to one of three groups: $400 \mathrm{mg}$ EPA-DHA, $2 \mathrm{~g}$ EPA-DHA or placebo oil in capsules.

\section{Excluded studies}

We did not consider a recently concluded study which examined the effects of 3-month EPA/DHA supplementation on depressed mood and cognitive function in adults aged 20-65 as participants were too young to meet inclusion criteria (Rogers 2005). There is another ongoing randomized trial in healthy young adults (Singhal 2004) that is also of an inappropriate age group for the purposes of our review.

\section{Risk of bias in included studies}

Not applicable

\section{Effects of interventions}

There is no evidence that omega 3 PUFA reduce the risk of cognitive impairment or dementia.

\section{A U THORS' CONCLUSIONS}

\section{Implications for practice}

On the basis of currently available evidence, omega 3 PUFA supplementation cannot be recommended for the explicit purpose of preventing cognitive impairment or dementia.

However, it is not uncommon in clinical practice to encounter well-meaning patients and their families who specifically enquire about dietary recommendations for lowering the risk of dementia. Evidence from large well-conducted population studies suggests that a high intake of saturated or trans-unsaturated fats increases, while fatty fish and marine

omega 3 PUFA consumption decreases the risk of cognitive impairment and incident dementia (Barberger-Gateau2002; Kalmijn 2004; Morris 2003a; Morris 2003b). Thus, in this regard, it is not unreasonable to encourage adequate consumption of fatty fish as part of general dietary recommendations that may also confer benefits of reducing the risk of stroke and heart disease (Friedland 2003).

\section{Implications for research}

Although biological and epidemiological studies support the utility of omega 3 PUFA in preventing cognitive impairment or dementia, there is a pressing need for randomized double-blind placebo-controlled trials to confirm or refute this premise. While risk reduction is an important measure, there are other issues in need of investigation. These include:

- The effects of omega 3 PUFA on sub-populations

- The effects of omega 3 PUFA source

- Optimal dose and exposure duration

- Sustenance of effect after cessation of omega 3 PUFA supplementation

- Whether there is a differential benefit on dementia risk for those with APOE-epsilon 4 compared with those without (Huang 2005).

- Whether omega 3 PUFA supplementation can retard or stop the progression of disease diagnosed at an early, mild stage (i.e. secondary prevention treatment trials)

- Whether therapy started in middle life has an advantage over therapy started in the 60 s or early 70 s.

\section{DISCUSSION}

Not applicable

\section{ACKNOW LEDGEMENTS}

The reviewers would like to acknowledge Dymphna Hermans, Coordinator, Cochrane Dementia and Cognitive Impairment Group,

Omega 3 fatty acid for the prevention of dementia (Review) 
and Katherine Hicks, Review Co-ordinator, Cochrane Dementia Cognitive Impairment Group, for advice in writing the protocol and assistance in the trial search, as well as Christine Derrick for providing consumer comments.

\section{R E F E R E N C E S}

\section{References to studies excluded from this review}

Rogers 2005 \{published data only\}

Rogers P. Impact of n-3 LCPUFAs on depressed mood and cognitive function. http://www.food.gov.uk/science/ research/researchinfo/nutritionresearch/optimalnutrition/ n05programme/n05listcognition/n05038/. 2005.

Singhal 2004 \{published data only\}

A Singhal. The influence of $\mathrm{n}-3$ fatty acid supplementation on cognitive and vascular function; a randomised, controlled trial. National Research Register 2004k.

\section{References to ongoing studies}

Dangour 2004 \{published data only\}

Dangour A. The OPAL study: Older people and n-3 long chain polyunsaturated fatty acids. Current Controlled Trials. http://www.controlled-trials.com/isrctn/trial///0/ 72331636.html 2005.

* Dangour A, The Opal Study. The OPAL Study: Older People And n-3 Long-chain polyunsaturated fatty acids. http://www.controlled-trials.com/isrctn/trial///0/ 72331636.html 2004.

Ludders J. Older People and n-3 long-chain polyunsaturated fatty acids. National Research Register. http:// www.nrr.nhs.uk/ViewDocument.asp?ID=N0530160356 2005.

Smithson WH. The OPAL Study. Old people and n-3 longchain polyunsaturated fatty acids. ISRCTN Register 2005.

van de Rest 2005 \{published data only\}

Ondine van de Rest. The MEMO study: Mental Health in Elderly Maintained with Omega-3. Current controlled trials. http://www.controlled-trials.com/isrctn/trial/\%7C/ 0/46249783.html 2005.

\section{Additional references}

\section{Akiyama 2000}

Akiyama H, Barger S, Barnum S, Bradt B, Bauer J, Cole GM, Cooper NR, Eikelenboom P, Emmerling M, Fiebich BL, Finch CE, Frautschy S, Griffin WS, Hampel H, Hull M, Landreth G, Lue L, Mrak R, Mackenzie IR, McGeer PL, O’Banion MK, Pachter J, Pasinetti G, Plata-Salaman C, Rogers J, Rydel R, Shen Y, Streit W, Strohmeyer R, Tooyoma I, Van Muiswinkel FL, Veerhuis R, Walker D, Webster S, Wegrzyniak B, Wenk G, Wyss-Coray T. Inflammation and Alzheimer's disease. Neurobiology of Aging 2000;21:383-421.

\section{Alderson 2004}

Alderson P, Green S, Higgins JPT, editors. Cochrane Reviewers' Handbook 4.2.2 [updated March 2004]. The Cochrane Library. John Wiley \& Sons, Ltd, Issue 1, 2004.

Bang 1971

Bang HO, Dyerberg J, Nielsen AB. Plasma lipid and lipoprotein pattern in Greenlandic west-coast Eskimos. Lancet 1971;1:1143-5.

\section{Barberger-Gateau2002}

Barberger-Gateau P, Letenneur L, Deschamps V, Peres K, Dartigues JF, Renaud S. Fish, meat and risk of dementia: cohort study. British Medical Journal 2002;325:932-3.

\section{Beck 1961}

Beck AT, Ward C, Mendelson M. An inventory for measuring depression. Archives of General Psychiatry 1961; 4:561-71.

\section{Calon 2004}

Calon F, Lim GP, Yang F, Morihara T, Teter B, Ubeda O, Rostaing P, Triller A, Salem N, Ashe KH, Frautschy SA, Cole GM. Docosahexaenoic acid protects from dendritic pathology in an Alzheimer's disease mouse model. Neuron 2004;43:633-45.

\section{Conquer 2000}

Conquer JA, Tierney MC, Zecevic J, Bettger WJ, Fisher RH. Fatty acid analysis of blood plasma of patients with Alzheimer's disease, other types of dementia, and cognitive impairment. Lipids 2000;35:1305-12.

\section{Cummings 2004}

Cummings JL. Alzheimer's Disease. New England Journal of Medicine 2004;35:156-67.

\section{Din 2004}

Din JN, Newby DE, Flapan AD. Omega 3 fatty acids and cardiovascular disease - fishing for a natural treatment. British Medical Journal 2004;328:30-35.

\section{DSM III-R}

American Psychiatric Association. Diagnostic and Statistical Manual of Mental Disorders. 3th edition revised. Washington D.C.: American Psychiatric Association, 1987.

\section{DSM-IV}

American Psychiatric Association. Diagnostic and Statistical Manual of Mental Disorders. 4th Edition. Washington D.C.: American Psychiatric Association, 1994.

\section{Dyerberg 1975}

Dyerberg J, Bang HO, Hijorne N. Fatty acid composition of the plasma lipids in Greenland Eskimos. American Journal of Clinical Nutrition 1975;28:958-66. 
Engelhart 2002

Engelhart MJ, Geerlings MI, Ruitenberg A, van Swieten JC, Hofman A, Witteman JCM, Breteler MMB. Diet and the risk of dementia: does fat matter? The Rotterdam Study. Neurology 2002;59:1915-21.

Friedberg 1998

Friedberg CE, Janssen MJ, Heine RJ, Grobbee DE. Fish oil and glycemic control in diabetes: a meta-analysis. Diabetic Care 1998;21:494-500.

\section{Friedland 2003}

Friedland RP. Fish consumption and the risk of Alzheimer disease. Archives of Neurology 2003;60:923-4.

Gamoh 1999

Gamoh S, Hashimoto M, Sugioka K, et al.Chronic administration of docosahexanoic acid improves reference memory-related learning ability in young rats. Neuroscience 1999;93:237-41.

Gompertz 1993

Gompertz P, Pound P, Ebrahim S. The reliability of stroke outcome measurement. Clinical Rehabilitation 1993;7: $290-6$.

Guallar 2002

Guallar E, Sanz-Gallardo T, van't Veer P, et al.Mercury, fish oils and the risk of myocardial infarction. New England Journal of Medicine 2002;347:1747-54.

Hamilton 1960

Hamilton M. Rating scale for depression. Journal of Neurology, Neurosurgery \& Psychiatry 1960;23:56-62.

He 2002

He K, Rimm EB, Merchant A, Rosner BA, Stampfer MJ, Willett WC, Ascherio A. Consumption and risk of stroke in men. JAMA 2002;288:3130-6.

Heude 2003

Heude B, Ducimetiere P, Berr C. Cognitive decline and faty acid composition of erythrocyte membranes - The EVA study. American Journal of Clinical Nutrition 2003;77: 803-8.

Hibbeln 1998

Hibbeln JR. Fish consumption and major depression. Lancet 1998;351:1213.

Hofman 1997

Hofman A, Ott A, Breteler MM, Bots ML, Slooter AJ, van Harskamp F, van Duijn CN, Van Broeckhoven C, Grobbee DE. Atherosclerosis, apolipoprotein $\mathrm{E}$ and the prevalence of dementia and Alzheimer's disease in the Rotterdam study. Lancet 1997;349:151-4.

\section{Hooper 2004}

Hooper L, Thompson RL, Harrison RA, Summerbell CD, Moore H, Worthington HV, Durrington PN, Ness AR, Capps NE, Davey Smith G, Riemersma RA, Ebrahim SBJ. Omega 3 fatty acids for prevention and treatment of cardiovascular disease. The Cochrane Database of Systematic Reviews 2004 2004, Issue 3 Art No:CD003177. DOI:10.1002/14651858.CD003177.pub2.[Art. No.: CD003177. DOI: 10.1002/14651858.CD003177.pub2]
Huang 2005

T.L. Huang, P.P. Zandi, K.L. Tucker, A.L Fitzpatrick, L.H. Kuller, L.P. Fried, G.L. Burke, M.C. Carlson. Benefits of fatty fish on dementia risk are stronger for those without APOE epsilon-4. Neurology 2005;65:1409-1414.

Iso 2001

Iso H, Rexrode KM, Stampfer MJ, Manson JE, Colditz GA, Speizer FE, Hennekens $\mathrm{CH}$, Willett WC. Intake of fish and omega-3 fatty acids and risk of stroke in women. JAMA 2001;285:304-12.

Juni 2001

Juni P, Altman DG, Egger M. Assessing the quality of controlled clinical trials. British Medical Journal 2001;323: 42-6.

\section{Kalmijn 1997}

Kalmijn S, Launer LJ, Ott A, Witteman JCM, Hofman A, Breteler MMB. Dietary fat intake and the risk of incident dementia in the Rotterdam Study. Annals of Neurology 1997;42:776-82.

Kalmijn 2004

Kalmijn S, van Boxtel MPJ, Ocké M, Verschuren WMM, Kromhout D, Launer LJ. Dietary intake of fatty acids and fish in relation to cognitive performance at middle age. Neurology 2004;62:275-80.

Kyle 1999

Kyle DJ, Schaefer E, Patton G, Beiser A. Low serum docosahexanoic acids is a significant risk factor for Alzheimer's disease. Lipids 1999;34:245S.

\section{Laurin 2003}

Laurin D, Verreault R, Lindsay J, Dewailly E, Holub BJ. Omega 3 fatty acids and risk of cognitive impairment and dementia. Journal of Alzheimer Disease 2003;5:315-322.

\section{McKhann 1984}

McKhann G, Drachman D, Folstein M, Katzman R, Price D, Stadlan EM. Clinical diagnosis of Alzheimer's disease: report of the NINCDS-ADRDA Work Group under the auspices of Department of Health and Human Services Task Force on Alzheimer's Disease. Neurology 1994;34:939-944.

Montori 2000

Montori VM, Farmer A, Wollan PC, Dinneen SF. Fish oil supplementation in type 2 diabetes: a quantitative systematic review. Diabetic Care 2000;23:1407-15.

\section{Morris 2003a}

Morris MC, Evans DA, Bienas JL, Tangney CC, Bennett DA, Wilson RS, Aggarwal N, Schneider J. Dietary fish and the risk of incident Alzheimer Disease. Archives of Neurology 2003a; 60:194-200.

\section{Morris 2003b}

Morris MC, Evans DA, Bienias JL, Tangney CC, Bennett DA, Wilson RS, Aggarwal N, Schneider J. Consumption of fish and n-3 fatty acids and risk of incident Alzheimer Disease. Archives of Neurology 2003b;60:940-946.

\section{Morris 2005}

Morris MC, Evans DA, Tangney CC, Bienias JL, Wilson RS. Fish consumption and cognitive decline with age in a large community study. Archives of Neurology 2005;62:1-5. 


\section{Nourhasémi 2000}

Nourhasémi F, Gillette-Guyonnet S, Andrieu S, Ghisolfi A, Ousset PJ, Grandjean H, Grand A, Pous J, Vellas B, Albarede JL. Alzheimer disease: protective factors. American Journal of Clinical Nutrition 2000;71:643S-649S.

\section{Petersen 2001}

Petersen RC, Doody R, Kurz K, Mohs RC, Morris JC, Rabins PV, Ritchie K, Rossor M, Thal L, Winblad B. Current concepts in mild cognitive impairment. Archives of Neurology 2001;58:1985-92.

\section{Ritchie 2000}

Ritchie K, Touchon J. Mild cognitive impairment: conceptual basis and current nosological status. Lancet 2000;355:225-8.

\section{Ruggiero 2004}

Ruggiero C, Cherubini A, Andres-Lacueva C, Martin A, Lauretani F, Di Iorio A, Bartali B, Bandinelli S, Corsi A, Senin U, Ferrucci L. Low plasma N-3 fatty acids and dementia in community dwelling elderly subjects: the invecchiare in chianti (inchianti) study. The Journal of Nutrition, Health and Aging 2004;8(4):263.

\section{Stoll 1999}

Stoll AL, Severus E, Freeman MP, Rueter S, Zboyan HA, Diamond E, Gress KK, Marangell LB. Omega 3 fatty acids in bipolar disorder: a preliminary double-blind, placebocontrolled trial. Archives of General Psychiatry 1999;56(5): 407-12.

\section{Terano 1999}

Terano T, Fujishiro S, Ban T, et al.Docosahexanoic acid supplementation improves the moderately severe dementia from thrombotic cerebrovascular diseases. Lipids 1999;34: 345S-346S.

\section{Tully 2003}

Tully AM, Roche HM, Doyle R, Fallon C, Bruce I, Lawlor B, Coakley D, Gibney MJ. Low serum cholesteryl esterdocosahexaenoic acid levels in Alzheimer's disease: a casecontrol study. British Journal of Nutrition 2003;89:483-9.

\section{Ware 1993}

Ware JE, Snow KK, Kosinski, Gandek B. SF-36 Health Survey: Manual and 1993 Interpretation Guide. New England Medical Center, Health Institute 1993.

\section{WHO 1992}

World Health Organisation. The ICD-10 Classification of Mental and Behavioural Disorders: Clinical Description and Diagnostic Guidelines. Geneva: World Health Organisation, 2002.

\section{Yehuda 1996}

Yehuda S, Rabinovitz, Carasso RL, et al.Essential fatty acids preparation (SR-3) improves Alzheimer's patients quality of life. International Journal of Neuroscience 1996;87:141-9.

\section{Zigmond 1983}

Zigmond AS, Snaith RP. The Hospital Anxiety and Depression Scale. Acta Psychiatrica Scandinavica 1983;67: 361-70.

* Indicates the major publication for the study 


\section{CHARACTERISTICS OF STUDIES}

\section{Characteristics of excluded studies [ordered by study ID]}

\begin{tabular}{ll}
\hline Study & Reason for exclusion \\
\hline Rogers 2005 & $\begin{array}{l}\text { This study has been completed; write-up is pending results of blood fatty acid assays. However, via personal commu- } \\
\text { nication (October 2005) we know the triallists recruited only younger age adults (20-65 years) with mild to moderate } \\
\text { depression }\end{array}$ \\
\hline Singhal 2004 & This is an ongoing study scheduled for completion 30 Sep 2006. Recruited only younger age participants \\
\hline
\end{tabular}

Characteristics of ongoing studies [ordered by study ID]

Dangour 2004

\begin{tabular}{|c|c|}
\hline Trial name or title & Older People And n-3 Long-chain poluunsaturated fatty acids \\
\hline \multicolumn{2}{|l|}{ Methods } \\
\hline Participants & $\begin{array}{l}\text { Healthy, cognitively normal (baseline MMSE greater than 23) adults aged 70-79 years. } \\
\text { Recruited from } 20 \text { general practices. }\end{array}$ \\
\hline Interventions & $\begin{array}{l}\text { 1. } 0.7 \mathrm{~g} \mathrm{n}-3 \text { oil }(0.5 \mathrm{~g} \text { DHA/ } 0.2 \mathrm{~g} \text { EPA) daily for } 24 \text { months } \\
\text { 2. Placebo }\end{array}$ \\
\hline Outcomes & $\begin{array}{l}\text { 1. California Verbal Learning Test (primary outcome) } \\
\text { 2. Immediate and delayed recall } \\
\text { 3. Verbal fluency } \\
\text { 4. Digit span backwards } \\
\text { 5. Digit symbol } \\
\text { 6. Spatial memory } \\
\text { 7. Timed letter search } \\
\text { 8. Simple and choice reaction time } \\
\text { 9. Prospective memory } \\
\text { 10. Dual-task performance }\end{array}$ \\
\hline Starting date & $01 / 03 / 2004$ \\
\hline Contact information & $\begin{array}{l}\text { Dr Alan Dangour } \\
\text { London School of Hygiene and Tropical Medicine } \\
\text { Keppel Street } \\
\text { London } \\
\text { United Kingdom } \\
\text { WC1E 7HT }\end{array}$ \\
\hline
\end{tabular}


Dangour 2004 (Continued)

Notes

van de Rest 2005

\begin{tabular}{|c|c|}
\hline Trial name or title & Mental Health in Elderly Maintained with Omega-3 \\
\hline \multicolumn{2}{|l|}{ Methods } \\
\hline Participants & Older persons aged $>65$ years with baseline MMSE $>21$ \\
\hline Interventions & $\begin{array}{l}\text { 1. } 400 \mathrm{mg} \text { EPA-DHA for } 26 \text { weeks } \\
\text { 2. } 2 \mathrm{~g} \text { EPA-DHA for } 26 \text { weeks } \\
\text { 3. Placebo }\end{array}$ \\
\hline Outcomes & $\begin{array}{l}\text { 1. RAVLT Rey Auditory Verbal learning test (primayr outcome) } \\
\text { 2. Weschler forward and backward digit span } \\
\text { 3. Trails A and B } \\
\text { 4. Stroop test } \\
\text { 5. Fluency test } \\
\text { 6.. Quality of life } \\
\text { (WHOQOL-BREF) }\end{array}$ \\
\hline Starting date & $01 / 10 / 2005$ \\
\hline Contact information & $\begin{array}{l}\text { Ondine van de Rest } \\
\text { Division of Human Nutrition } \\
\text { Wageningen University } \\
\text { Postbus } 8129 \\
\text { Wageningen } \\
6700 \text { EV } \\
\text { Netherlands }\end{array}$ \\
\hline Notes & \\
\hline
\end{tabular}




\section{DATA ANDANALYSES}

This review has no analyses.

\section{WHAT'S NEW}

Last assessed as up-to-date: 11 November 2005.

Date Event Description

6 November 2008 Amended Converted to new review format.

\section{H I S T O R Y}

Protocol first published: Issue 3, 2005

Review first published: Issue 1, 2006

\begin{tabular}{l|ll}
\hline Date & Event & Description \\
\hline 12 November 2005 & New citation required and conclusions have changed & Substantive amendment \\
\hline
\end{tabular}

\section{CONTRIBUTIONSOFAUTHORS}

WL: initiated and drafted the protocol. He will be involved in trial search and selection, adjudication of disagreements in data extraction, data entry, statistical analyses, and writing of the final review.

JG, JVN, AD: provided an equal input into the conceptual development and editing of the protocol, and was involved in data interpretation and review of the final draft.

Both JG and JVN also searched trials, selected trials, and extracted data, while AD was involved in data extraction.

Contact Editor: Peter Whitehouse

Consumer Editor: Christine Derrick

This review has been peer reviewed in November 2005. 


\section{DECLARATIONSOF INTEREST}

Alan Dangour is the principal investigator of the Older People And n-3 Long-chain polyunsaturated fatty acids (OPAL) study.

\section{N DEX TERMS}

Medical Subject Headings (MeSH)

Cognition Disorders [* prevention \& control]; Dementia [ ${ }^{*}$ prevention \& control]; Fatty Acids, Omega-3 [*therapeutic use]; Randomized Controlled Trials as Topic

\section{MeSH check words}

Aged; Humans 